\title{
The social media innovation challenge in the public sector
}

\author{
Ines Mergel
}

\begin{abstract}
The use of social media applications has been widely accepted in the U.S. government. Many of the social media strategies and day-to-day tactics have also been adopted around the world as part of local Open Government Initiatives and the worldwide Open Government Partnership. Nevertheless, the acceptance and broader adoption of sophisticated tactics that go beyond information and education paradigm such as true engagement or networking strategies are still in its infancy. Rapid diffusion is challenged by informal bottom-up experimentation that meets institutional and organizational challenges hindering innovative tactics. Going forward governments and bureaucratic organizations are also facing the challenge to show the impact of their social media interactions. Each of these challenges is discussed in this article and extraordinary examples, that are not widely adopted yet, are provided to show how government organizations can potentially overcome these challenges.
\end{abstract}

Keywords: Social networking, social media, ICT adoption

\section{Introduction}

Social media technologies have been adopted by U.S. federal government agencies and departments especially in the executive branch - at a rapid pace $[4,31]$. This development was partly driven by President Obama's Transparency and Open Government memo that mandates executive departments and agencies to "harness new technologies" [36]. Other drivers include the increased use of social networking services among citizens and their expectations to receive government information "where they are" directly delivered to their Facebook or Twitter feeds [9,20].

These new technologies include social media tools that allow bidirectional interactions between government and its stakeholders [3]. Social media technologies in the public sector include for example blogs as vehicles for increased transparency of an agencies actions, to address issues with their audiences, and to mainly pass on information to the public [24,55]; the micro-blogging service Twitter to inform journalists and professional groups and direct them to longer updates on a government's website [53].

The recent use of social media applications in the public sector can be defined as the fifth wave of information and communication technology (ICT) adoption in government, following the previous four waves of mainframes in the 1950s-1960s, central timeshare systems (1970s-1980s), minicomputers and LAN (1980-1990s), online e-services (1990s-2000s) [4]. The emergence of every new wave of ICTs has brought expectations of advantages for government efficiency and effectiveness, but also challenges to the standard operating procedures, and had to be incorporated into the existing institutional and organizational frameworks. 
This article provides insights into the ongoing and future tensions between a mandate for change and innovation, and the mitigation of risks to support responsible and effective use of social technologies in the public sector.

\section{Current state of social media acceptance in the U.S. government}

The use of social media as additional communication channels with government's diverse stakeholders has increased in the U.S. federal agencies and departments. Government organizations in the U.S. federal government were encouraged to use innovative technologies, such as social media, social computing and collaboration platforms to support their mission. They are not as widely adopted as other forms of public ICTs, instead on all levels of government social media tools are used as additional and oftentimes parallel communication channels to the existing forms of interaction with the diverse audiences of government. Based on the mandate of the Open Government Initiative (OGI), the adoption of these innovative technologies is used for three different purposes: (1) to increase transparency, (2) to support inter- and intra-organizational collaboration and (3) to enable innovative forms of public participation and engagement [37,49].

A parallel development occurs to the official top-down mandate: citizens' use of social networking sites has increased. PEW's Internet and American Life Project reports that $65 \%$ of online adults use social networking sites in the U.S. - in comparison only $8 \%$ of online adults used social networking sites in 2005 [23]. While most online adults mainly use social networking sites to stay in touch with their family members and friends [45], the trend indicates that many citizens pay attention to the news updates their online contacts are posting and are therefore exposed to information and news that are deemed to be important to their contacts. A recent study found that $70 \%$ of online adults indeed receive most of their news from links posted through their personal social network on Facebook, and 36\% receive news and information via Twitter [41]. These trends, paired with a recent survey that indicates that only $19 \%$ of Americans trust government, indicate the importance of social networking sites and a shift in attention towards socially vetted information and news, instead of a focus and trust in official and formally communicated information through official government channels $[12,40]$.

The use of social media applications is therefore mainly driven by innovative citizen use and government organizations are slow in adopting the tools to connect to their audiences where they prefer to receive information and news - on social networking sites [48]. As of May 2012, the 698 departments, agencies, and initiatives of the U.S. federal government have created 488 Facebook pages, 363 Twitter accounts, 247 YouTube channels, and 71 Flickr pages to promote their online content and connect to their audiences. In addition, the Department of Defense alone has created 2,468 Facebook pages, 653 Twitter accounts, 448 YouTube channels, and 427 Flickr accounts [30]. Agencies are also testing alternative social media platforms, such as blogs [24,55], but there is a clear convergence observable towards these four aforementioned platforms [31].

Government agencies and departments do not replace their existing communication mission or their official websites as their main information and education tool with full control over technological features, ease of data archiving and access than social media applications that are hosted by third party providers.

Instead, research has shown that government agencies are using a diverse set of social media tactics, that are the daily routines on how to use social media applications, in four different purposes [10,32]. The main use is to broadcast existing web content out through the additional social media channels. This tactic aligns well with the mission of most government agencies and helps to fulfill their informational and educational mandate. In addition, government agencies are slowly trying to pull information in from 
citizens through social media channels. This second tactic is used to increase participation by asking citizens to provide their insights, polling their opinions or crowdsourcing additional content. Rarely do government bodies allow themselves to actively (or even passively) participate in actual networking and interactive engagement. This third tactic can be used to be part of issue discussions, moving from a push, or pull tactics to an interactive mingling tactic. The final tactic that is rarely observable is used for actual transactions - conducting government services through social media applications [10,34]. Following the current call to increase and improve online customer service and experience however will lead government agencies to rethink and reinvent their online service deliver and in the future they might be willing to increase the fourth tactic [42].

The main challenge for government remains: Social media technologies are changing at a rapid pace and platform providers have full control over technological features, are changing or abandoning services without prior notice, oftentimes without regard for the already invested resources into the service [28]. Moreover, government is faced with expectations to adapt its communication behavior to the changing social online interactions its stakeholders are gotten used to in their personal interactions. Expectations to innovate using social media at the same rate as other sectors or private citizens are impossible for government to meet.

\section{Social media innovation dilemma in the public}

The use of social media in government is accompanied with expectations to innovate the online interactions between government and its stakeholders. Prominent supporters claim that social media has a democratizing effect and provides those parts of the population who were never involved in policy making with an opportunity to be heard [15]. Others claim that social media is highly biased and that it can be misused to game public opinion polling [22]. Government organizations are facing the dilemma of innovating their digital interactions using social media outlets within the existing hierarchical settings.

Traditionally, innovation in government is largely driven by policy makers, presidential mandates or vendors hired to improve the effectiveness and efficiency of public service delivery and interactions [5]. Especially when it comes to e-Government service delivery and communication with constituencies, innovative practices are oftentimes driven by external vendors who are replicating specific services across many different departments and agencies and are only incrementally adjusting to the local requirements [21]. The innovation dilemma is not unique to the adoption of social media use, but in comparison to previous waves of (mostly internal) ICT adoption practices social media online interactions are for the first time publicly observable. Every misstep or unresponsiveness is immediately called out by the public and replicated through each social networking site.

As an example, the openness and the fast pace of interactions through Facebook or Twitter are challenging the existing rather slow moving responsiveness paradigm in government. As an example, requests for records based on the Freedom of Information Act (FOIA) have to be answered within 10 days (or 30 days in some cases). The pace of interactions on social networking sites is almost happening in real time, leaving little room for research, deliberation, and a formal vetting process on the side of government.

Similar to the claims of the open innovation literature, most innovations in government are internally focused [6]. They are allowing for incremental adjustments to the status quo, but are not radically changing the existing communication paradigm. Instead, government internal logic is kept in tact and innovation rarely emerging ad hoc. The notion of adopting an innovation that has its focus on an external- 
user or social networking provider - initiator is rarely observable in government and is accompanied by a "not-invented-here" aversion to change.

The adoption of social media has in some cases however followed a three-step adoption approach: several social media initiatives were a result of early experimentation initiated from within government agencies. Accounts on social networking platforms were set up outside the formal ICT infrastructure by so-called intrapreneurs, who were willing to test and experiment on third-party platforms outside the officially sanctioned processes [33]. Social media policies and guidelines then followed this high-risk intrapreneurial behavior and retroactively corrected unsanctioned innovations [10].

Early experimentations took on an open innovation approach to social media innovation. Early adopters followed the external logic they observed from their stakeholders and other organizations within and outside of government. The tools are developed outside government's direct intervention. That means features and technological changes are defined and adjusted by third parties, with very little input by government. Instead, most platforms are either changing their interfaces based on citizens' interactions, such as Twitter's hashtags that were "invented" by its users [13]. Or they change based on business needs of social networking providers. Innovations in terms of behavioral and technological uses are therefore located outside of government's decision-making processes.

Other types of social media innovation occur based on behavioral changes of online stakeholders: users are creating and agreeing on so-called online memes, such as hashtags on Twitter, that are used to communicate about one specific issue. Hashtags are searchable keywords, which are frequently used in Twitter updates and are highlighted with the \#-sign and are searchable. These memes evolve oftentimes without formal direction and connect all those interested parties who want to be involved in the ongoing conversations. Innovative insights can be accumulated in these conversations and government needs to find ways to extract meaningful insights. Online memes are oftentimes the locus of innovations that can potentially be useful for government. Failing to read or pay attention to these social awareness streams have in the past led to delayed responses by governments - as the examples of the Arab Spring uprisings or the Occupy movements have shown [43]. As an example, the U.S. Department of State has been at the forefront of using Twitter hashtags to answer citizens' and journalists' questions and is moving to an online forum in which they are publicly providing explanations as well as interpretations of their policy making decisions or public diplomacy efforts. The hashtag \#AskState can be seen as a mechanism to provide insights into decision making processes, but can also be used as a form for the public to provide innovative insights into citizens' needs [18].

Allowing government to be "social" by using social media applications means to strike a balance between innovative behavior of citizens and their interactions with government and considering how to integrate these innovations into government operations. The implication of moving into social media use means that government agencies need to stay open for unpredictable social behavior of citizens and movements, while at the same time frequently respond to technological changes that keep challenging the status quo.

The potential of social media use for meaningful, multi-directional exchanges between government and its diverse audiences do not fit the highly regulated and practiced top-down decision-making and broadcasting culture. The tension and challenges that remain include radical transparency approaches, the locus and focus of innovation creation in government, as well as the existing organizational routines and learned practices that need to be overcome to use social media as a governance mechanism. Finally, appropriate metrics to analyze and interpret online interactions and conversations is a challenge that government organizations have yet to overcome. Each of the challenges and potential solutions are discussed in the following. 


\subsection{Challenge 1: Expectations of radical transparency}

The use of social media applications in the public sector has created high expectations for new forms of transparency, publicness of once published information, and accountability that is challenging government's static information and education paradigm [44]. Citizens are redefining their role in a distributed democracy: Providing feedback to government every four years (and potentially more frequently on the local level) is no longer a driver for major change and does not stay the only opportunity to show how citizens feel about their government $[16,48]$. Instead social technologies provide instant responsiveness cycles for direct feedback and increase the expectations for future exchanges. As soon as a government agency is willing to enter its citizens' social awareness stream in form of their Facebook or Twitter newsfeeds, the expectation on the citizen side increases for real time exchanges and responses to comments and questions posted. Recent crowdsourcing efforts of citizen journalists during the Occupy movements have shown that government needs to pay attention to this new form of "expressed" citizenship [19].

In government realm, transparency is oftentimes seen from a privacy standpoint. Either a government record is sealed, private, and in need for protection from release to the public. Or it is public and therefore, the public or citizenry can apply for the right to obtain a copy through the Freedom of Information Act [52]. This approach has changed in recent discussions about privacy and the use of new technology [11]. In using social media there are several different layers of privacy. Privacy no longer includes official government interactions, but also how citizens interact with government social media content, how they share it through their network of contacts in semi-public spaces, such as walledgardened social networking sites. Online behavior or statements might not be perceived to be public, instead they are considered as expressions among friends. Nevertheless, they are always shared through the social network and what the original poster might consider or even restrict to post just to their friends, can easily be snowballing through the system and will become part of the government record. A recent Government Accountability Office (GAO) report highlighted the challenge between expectations for transparency and the necessity of protecting privacy of interactions given the changing landscape of new technologies [14].

The concept of radical transparency - a management approach - goes beyond the distribution of and access to government records after they were archived [14]. Instead, all decision making processes are made public - beyond the formal records in forms of memos. In a radical transparency approach each step a government agencies takes to arrive at a final output, such as a new policy, are expected to be transparent and accessible to the public.

While this term is oftentimes used as part of a blame management approach or for damage control in the political arena, being radically transparent can increase accountability of governing operations. Providing insights during the decision making process can help agencies to allow its stakeholders input and a mechanism to potentially stir the next steps into a direction that the stakeholders prefer. It can therefore serve as a corrective mechanism. Using social media applications can open new opportunities to move away from the traditional need to know approach to a need to share approach in government [7, 25]. Transparency then does not only increase accountability, but also increases early buy-in from citizens and in turn might lead to higher degrees of trust in government operations by allowing citizens to be part of the process.

First approaches towards radical transparency have recently been made - although initiated from outside of government. Wikileaks, a platform that allows users to anonymously submit government records, such as memos, emails or videos, published large amounts of government data. The platform 
providers see their role as intermediary to facilitate the submission of records by citizens and to provide access to the material to news organizations. As Roberts recently noted, although the technological changes in Internet technologies have eliminated many of the practical barriers to share information, the example of Wikileaks shows that these forms of seemingly unlimited online interactions are only an illusion of a new form of transparency [44]. The expectations of initiating political changes were not fulfilled and the platform has now been replaced by other forms of online leaks (for example, OpenLeaks.org).

There are many other approaches and applications that are currently been tested - with a lot of reluctance by governments. As an example, the issue reporting platform SeeClickFix.com has taken over a step in the radical transparency approach - in what the company calls "distributed democracy" [27]. It serves as an intermediary between government and citizens and provides a platform through which non-emergency issues are being reported. During every step of the workflow process government departments have the opportunity to provide insights into the operations, report progress in fixing the issues step-by-step and make their own progress publicly available. Government agencies in the United States are all in a very early stage and are either just starting to explore the available tools or are building their own vendor-based solutions. Most agencies allow reporting through a contact form or via telephone and the progress of the process remains a black box for the citizens.

These examples show that the tension between the public's expectation for radical transparency and government's challenges to create truly open access to its operations and decision-making processes persist. Initiatives are started outside of government by so-called civic hackers who create access to these newfound forms of citizenship for themselves; the majority of citizens are still excluded from this form of political process. Governments around the world have taken first steps to address the expectations and have started to create open data portals, such as the White House's data.gov initiative in the U.S. government [38]. Governments need to go beyond the mere provision of information or data and provide insights into every step of the decision making process, showing who provided input, how the input was processed, and then provide context that will help citizens understand the data.

\subsection{Challenge 2: Organizational challenges}

E-government itself can be seen an institutional innovation, however they describe the implementation of e-government services as a "muddling through" practice. Around the world, governments so far mostly provide basic transactions and information services and the authors observe a stagnation of services and innovations. This means that the previous wave of e-Government has not proven its promises and is seen as an immature technology: the initiatives set out to increase openness of government and to inform citizens better, but unfortunately most e-Government processes are stuck at the stage where they are merely disseminating information, instead of allowing for true interactions and engagement.

Social media on the other hand promises to not only improve dissemination of government information, but holds the potential for increases in interaction, transaction and based on the influx of innovative knowledge from stakeholders also for transformation of government processes.

However, the technological development moves extremely fast and challenges the existing standard operating procedures of traditional top-down organized government hierarchies. The existing communication paradigm of government agencies involves the following core principles: to inform the general public, generate and maintain their support, to provide information and services to specialized publics, such as professional groups, in the policy community, to gain attention and participation of the groups in their constituency, and to gain insights from readers. Following the existing bureaucratic control 
structures and top-down treatment of updates, governments therefore communicates with delays due to for editing, printing, and distribution formats. As Mahler and Regan note, citizens' use of social media applications, such as blogs, provide the illusion of 24/7 access [24]. The speed of responsiveness is however slowed down by rigorous editing processes characterized by layers of information vetting and formal bureaucratic command and control mechanisms of a traditional public relations approach. The potential for new forms of democratic experiences to engage with elite public managers in government is therefore stifled by the existing standard operating procedures. As a result this means that government organizations need to adapt organizational procedures and managerial oversight to curate content appropriate for social media applications to reach citizens in environments where they prefer to receive their information. A first attempt has been made in the U.S. federal government, where the General Services Administration (GSA) has evolved as the central agency that provides centralized institutional support for all other federal agencies. While content decisions are decentralized and part of each agency's own content vetting process, GSA provides guidance and best practices examples through HowTo.gov, a website designed to support social media decision making processes. This central support function is flexible enough to pick up new trends, such as new tools including Tumblr or Pinterst, while the agency is at the same time able to manage a certain degree of oversight and formal guidance.

Across all social technology platforms innovative forms of content creation, sharing and information emerges that leaves government in a reactive mode. The existing policies and regulations were created before the advent of social media applications. This includes for example the 2002 e-Government Act that provides guidelines to U.S. federal agencies to improve the management and promotion of electronic government services and processes [51]. All internal organizational processes are based on the existing - outdated - regulations and are no longer reflecting the changing landscape of social media technologies [1]. Government agencies are reluctant to jump on the bandwagon and are constantly gauging the need to mitigate the risks of unintended interactions and unforeseen use patterns. This leaves government IT professionals in the middle: between catering to the demands of their diverse audiences and the standard operating procedures of the known and well-practiced press release communication style [34].

Finally, social media adoption is oftentimes met with resistance and platitudes such as, "I don't understand Twitter: I don't need to know what you had for lunch", or "We can't engage on social media, it's a matter of national security.", are hindering a free flow of information into government, but also 'protect' government from accessing innovative insights from the public. Public managers are oftentimes claiming information overload as barrier for engagement and it is therefore necessary to move from an away archiving mentality to battle the fear of information overload and trying to hoard more and more information for future purposes. boyd has recently suggested a "Social Media Zen" approach [2]. In the context of government it means that government officials have to accept that it cannot possibly access all the information that is available through social media and cannot be part of all the conversations that involve their organization's issues. Instead, government should rely on the underlying crowdsourcing mechanisms and the fact that the most important topics will rise to the agenda and can then be picked up, facts can be injected into the ongoing discussion, instead of feeding into the fear economy [47]. A solution for this dilemma is as Zuboff suggests, elites and top managers in the public sector need to get behind social technologies and do not let negative stories effect the adoption process [56]. Top managers can also facilitate a change process that allows for experimentation. New forms of digital interaction will occur and can then influence the necessary institutional properties of government organizations [39].

Figure 1 summarizes how social media adoption in government can only lead to innovations in online interactions, when government organizations are allowed to experiment outside the existing rules 
and regulations. Over time, the organization follows changes in social behavior and updates rules and regulations. In turn, a higher degree of formalization occurs, behavioral variations across government organizations are minimized and less innovative behavior is observable.

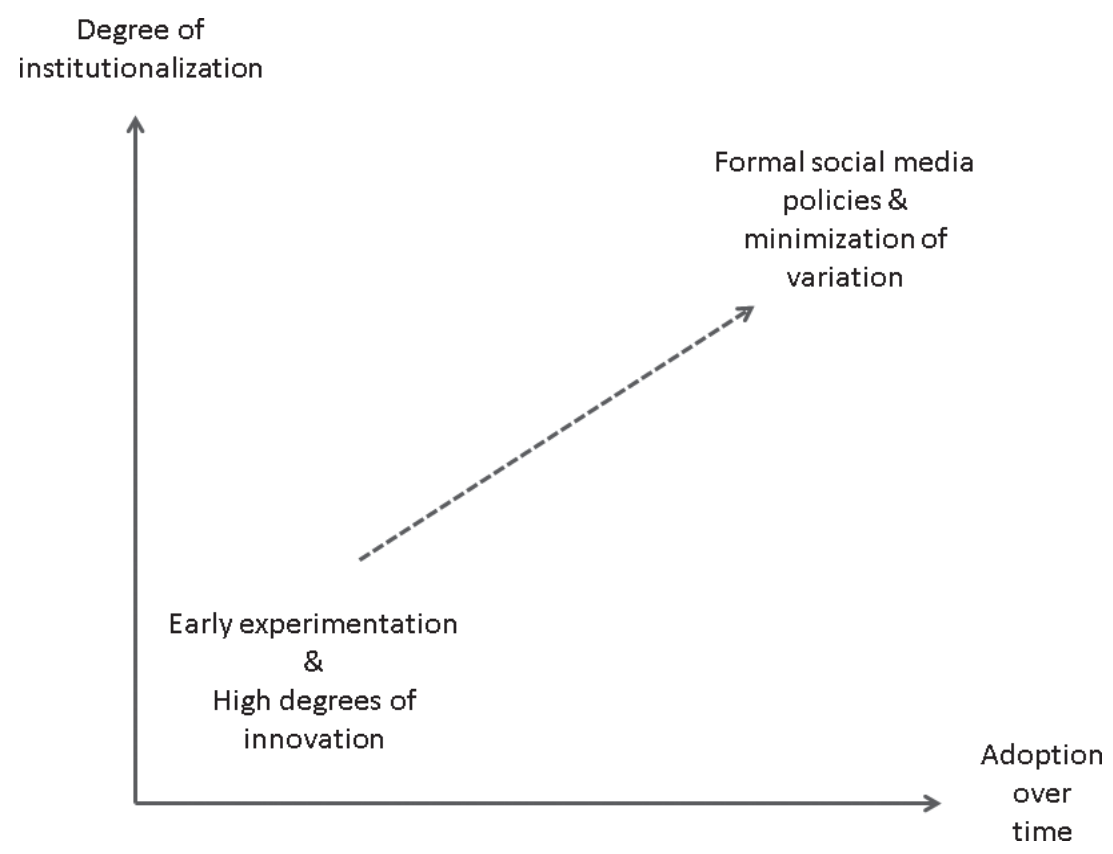

Fig. 1. Social media adoption in the public sector.

Nevertheless, a refocus on emerging trends in citizen behavior is needed. Currently social media is mainly seen as technological innovation and institutional support follows two main questions: What can the technology do? And, what are the features? Public managers need to focus on the behavior innovations instead of the technological features to be able to fulfill the public's expectations.

\subsection{Challenge 3: Measuring impact, effectiveness, efficiency}

The third challenge is to show evidence that the investments in additional resources and capacity are effective and efficient. Two main challenge persist: First, government agencies are lacking the truly interactive and transformative potential of social media. Second, challenges remain to measure effectiveness of social media interactions online.

Current social media tactics in government are mostly focused on broadcasting web content, but rarely on full engagement or on networking tactics. As a result, one social media director has recently described his agency's analytical strategy to the author as follows: "I would say we are measuring the 'Return on Ignorance'... ." He highlights that some of the existing regulations hinder creative analysis of user data and therefore many agencies are reluctant to actively measure their social media interactions beyond the number of comments on Facebook or they use the number of retweets their own content receives as an indicator for engagement.

The use of social media applications has now reached a critical point, where public managers need to go beyond the mere descriptive insights of click-throughs. Instead they need to understand how they can analyze conversation data, identify emerging issues, advocates and thought leaders among their audience 
members, and use social media as an ongoing governance mechanism beyond time-bound initiatives and short-term campaigns.

Traditional measurement techniques include for example Meletski's four step model to evaluate to what degree an agency's website is static, interactive, transactional or transformative [26]. Others measure performance of e-Government activities based on input, outcome, intermediate, end or ultimate outcome measures [46]. While the measurement of these dimensions is helpful for outside evaluators, the mere provision of numbers of even the most transactional and transformative service does not indicate how useful citizens themselves perceive the service. Some studies have found statistical significance as well as other positive outcomes of federal and local governments.' use of e-Government applications: For example, Tolbert and Mossberger found that providing government Internet services increases processbased trust by improving interactions with citizens and perceptions of responsiveness [50]. Other studies declare that e-Government itself is still at an early stage and has not obtained many of the expected outcomes (cost savings, downsizing, etc.) that the rhetoric of e-Government has promised [35].

West claims, "the e-government revolution has fallen short of its potential to transform service delivery and public trust in government. It does, however, have the possibility of enhancing democratic responsiveness and boosting beliefs that government is effective." [54, p. 15]. Hazlett and Hill emphasize that "Although there have been examples of very creative use of electronic government in the public sector, there have also been numerous spectacular failures; lack of evidence to support the claim that the use of technology in service delivery results in less bureaucracy and increased quality..." [17, p. 445]. Government agencies do not seem to be able to counteract this trend: A recent PEW Internet study found that only $22 \%$ of all U.S. citizens trust their government in 2010 - indicating that providing e-Government presences alone have not made a difference in imposing a positive image of government among citizens (Pew Research Center for the People and the Press, 2010).

Solutions for the measurement challenge present themselves mostly in form of vendor-driven software packages. Many social media directors in the public sector use services like Klout.com or Radian6, which don't allow users to understand what the metrics are that they use to measure sentiments and other types of social media interactions. Instead, social media managers need to look beyond the hype of freely available tools and develop metrics that truly measure their social influence and changes in perceptions of the public toward mission-oriented success factors. As an example, increasing the mere number of followers and contacts on a social media platform does not indicate that the mission of a government agency is fulfilled. This is similar to Titmuss' work on human blood donations: blood banks are willing to pay or raise the prize they pay donors to give blood. This attracts those people who don't necessarily give blood for the purpose of serving a higher good (and who are usually donating), but those who otherwise don't donate and are desperately attracted by the additional income. This in turn means that those are people with a diet that might not include expensive whole foods, but a rather high degree of processed foods and who are therefore prone to have a lower blood quality and potentially diseases. The result in short is: The quantity of new blood supply rises, but the quality overall is lowered. A parallel can be drawn to social media use in government: In times of political crisis or when polarizing public policies are discussed, government agencies attract "frequent flyers" or those citizens who are trying to game the system and are pushing their own topics [29]. Instead, understanding who the followers are and engaging those actors among them who are willing contribute their valuable insights to the conversation will be a much more powerful indicator. At the end, the right metrics will help government understand how to raise the quality of content and comments when they are engaging with the public via social media tools. 


\section{Outlook: Fluid social media use as a new governing mechanism}

The use of social media applications keeps challenging the existing status quo of government operations around the world. The examples in this article show that innovation occurs at the tip of the iceberg and is very slowly accepted as a new governance paradigm. Government is still in a hyper reactive mode: Social media tactics are changing as a response to changes in citizen behavior and expectations, but not necessarily as a direct result of a clear strategic move to support the existing mission.

Topics and controversies evolve around issues such as privacy and national security, instead of citizen relationship management and true online engagement and network that should be at the core of each agency's mission. Day-to-day practices such as participating in the reflexive feedback cycle are challenging the existing communication paradigm. Conversations about how data should be kept safe are diverting from the core purpose of social media platforms: connecting to citizens and with issues they are concerned about. Opponents of social media use in government far too often jump to the conclusion that interacting on social media jeopardizes national security. Social media is not Wikileaks and has received unfortunate attention by a service that has used the public's insights, but only provided an anonymous one-directional online mailbox system, instead of allowing multidirectional interactions with the submitted material [8].

The challenges and tensions prevail in government: Government organizations are treating social media interactions as pure broadcasting mechanisms and haven't recognized the power of social networking to engage and interact with the public yet. The future challenge - and opportunities - will be to move government operations into an open information paradigm that supports radical transparency, helps agencies understand how to adapt to behavioral changes online and use engagement measures that provide insights in the effectiveness and efficiency of their online interactions with citizens.

\section{References}

[1] J.C. Bertot, P.T. Jaeger and D.L. Hansen, The impact of policies on government social media usage: Issues, challenges, and recommendations. Government Information Quarterly, 2011. doi:10.1016/j.giq.2011.04.004.

[2] D. boyd, The Power of Fear in Networked Publics, in SXSW 2012: Austin, TX.

[3] D.M. boyd and N.B. Ellison, Social Network Sites: Definition, History, and Scholarship, Journal of Computer-Mediated Communication 13 (2007).

[4] S.I. Bretschneider and I. Mergel, Technology and Public Management Information Systems: Where have we been and where are we going, in: The State of Public Administration: Issues, Problems and Challenges, D.C. Menzel and H.J. White, eds, M.E. Sharpe, Inc.: New York, 2010, pp. 187-203.

[5] L. Brown and S.P. Osborne, Risk and Inovation, Public Management Review 10(5) (2013), p. DOI: 10.1080/14719037. 2012.707681.

[6] H.W. Chesbrough, Open innovation: the new imperative for creating and profiting from technology, 2003, Cambridge, MA: Harvard Business Press.

[7] S.S. Dawes, A.M. Cresswell and T.A. Pardo, From "Need to Know" to "Need to Share": Tangled Problems, Information Boundaries, and the Building of Public Sector Knowledge Networks, Public Administration Review 69(3) (2009), 392402.

[8] Deputy Secretary of Defense Directive-Type Memorandum (DTM) 09-026 - Responsible and Effective Use of Internetbased Capabilities, 2011.

[9] W. Doll and G. Torkzadeh, The Relationship of MIS Steering Committees to Size of Firma and Formalization of MIS Planning, Communications of the ACM 30(11) (1987), 972-978.

[10] B. Dunn, Best Buy's CEO on Learning to Love Social Media, Harvard Business Review, December 2010, pp. 43-48.

[11] S. Dutta, Managing Yourself: What's Your Personal Social Media Strategy, Harvard Business Review, 2010.

[12] Galupp, Trust in Government. 2011; Available from: http://www.gallup.com/poll/5392/trust-government.aspx.

[13] L. Gannes, The Short and Illustrious History of Twitter \#Hashtags. GigaOm, 2010.

[14] GAO, Federal Law Should Be Updated to Address Changing Technology Landscape, G.A. Office, Editor 2012, United States Congress: Washington, D.C. 
[15] M. Gladwell and C. Shirky, From Innovation to Revolution: Do Social Media Make Protests Possible? Foreign Affairs, 2011.

[16] S. Gregory, Cory Booker: The Mayor of Twitter and Blizzard Superhero. Time.com, 2010.

[17] S.-A. Hazlett and F. Hill, E-government: the realities of using IT to transform the public sector, Managing Service Quality 13(6) (2003), 445-452.

[18] A. Howard, \#AskState: U.S. State Department to take questions from Twitter at the podium, in Gov20.govfresh.com 2012, O'Reilly Radar: Washington, D.C.

[19] A. Ignatius, Disney CEO Robert A. Iger: Technology, Tradition and The Mouse. Harvard Business Review, July-August 2011, pp. 112-117.

[20] C.M. Judd, E.R. Smith and L.H. Kidder, Research methods in social relations, 1991 Fort Worth (TX): Holt, Rinehart, and Winston.

[21] D. Lazer et al., The multiple institutional logics of innovation, International Public Management Journal 14(3) (2011), 311-340.

[22] Y.-R. Lin, J.P. Bagrow and D. Lazer, More Voices Than Ever? Quantifying Media Bias in Networks, in: Conference on Weblogs and Social Media, P.o.t.F.I.A.C.o.W.a.S. Media, Editor 2011: Barcelona, Spain, pp. 193-200.

[23] M. Madden and K. Zickuhr, 65\% of online adults use social networking sites, 2011.

[24] J. Mahler and P.M. Regan, Federal Agency Blogs: Agency Mission, Audience, and Blog Forms, Journal of Information Technology and Politics 8(2) (2011), 163-176.

[25] A.J. Meijer, D. Curtin and M. Hillebrandt, Open government: connecting vision and voice, International Review of Administrative Sciences 78(1) (2012), 10-29.

[26] J. Melitski, Capacity and E-Government Performance: An Analysis Based on Early Adopters of Internet Technologies in New Jersey, Public Performance and Management Review 26(4) (2003), 376-390.

[27] I. Mergel, Distributed Democracy: SeeClickFix.Com for Crowdsourced Issue Reporting, 2012.

[28] I. Mergel, Facebook forces cities to rename their pages. Social media in the public sector blog, 2012.

[29] I. Mergel, "The Gift Relationship: From Human Blood to Social Policy" revisited for Government 2.0, in Social media in the public sector, I. Mergel, Editor 2010: Syracuse, NY.

[30] I. Mergel, A manager's guide to designing social media strategies in the public sector, in: Using Technology - Special Report, I.C.f.t.B.o. Government, Editor 2012: Washington, D.C.

[31] I. Mergel, Social Media in the Public Sector: Participation, Collabroation, and Transparency in the Networked World2012, San Francisco: Jossey-Bass.

[32] I. Mergel, The use of social media to dissolve knowledge silos in government, in: The Future of Public Administration, Public Management, and Public Service Around the World, R. O’Leary, S. Kim and D. VanSlyke, eds, 2011.

[33] I. Mergel and S. Bretschneider, Theoretical Model of Adoption Process with Application to Social Media Practices in the Public Sector: Where the formal and informal organizations meet! under review, 2012.

[34] A. Mislove et al., Pulse of the Nation: U.S. mood throughout the day inferred from Twitter 2010 [cited 2010; Available from: http://www.ccs.neu.edu/home/amislove/twittermood/.

[35] M.J. Moon, The Evolution of E-Government among Municipalities: Rhetoric or Reality? Public Administration Review 62 (2002), 424-433.

[36] B. Obama, Transparency and Open Government: Memorandum for the Heads of Executive Departments and Agencies, Whitehouse Blog, 2009.

[37] Office of Management and Budget, The Accountable Government Initiative - an Update on Our Performance Management Agenda, O.o.M. Budget, Editor 2010, The White House: Washington, DC.

[38] Open Government Partnership. 2012; Available from: http://www.opengovpartnership.org/.

[39] W.J. Orlikowski, Using Technology and Constituting Structures: A Practice Lens for Studying Technology in Organizations, Organization Science 11(4) (2000), 404-428.

[40] PEW, Distrust, Discontent, Anger and Partisan Rancor: The People and Their Government. 2010.

[41] Pew Research Center's Project for Excellence in Journalism, The State of News Media 2012: What Facebook and Twitter Mean for News, 2012.

[42] T.H. Poister and J.C. Thomas, The Wisdom of Crowds: Learning from Administratorsâ $€^{\mathrm{TM}}$ Predictions of Citizen Perceptions, Public Administration Review 67(2) (2007), 279-289.

[43] A. Roberts, Why the Occupy Movement Failed, Public Administration Review 72(5) (2012), 754-762.

[44] A. Roberts, WikiLeaks: The Illusion of Transparency, International Review of Administrative Sciences 78(1) (2012), $116-133$.

[45] A. Smith, Why Americans use social media, 2011.

[46] G.N.L. Stowers, Measuring the Performance of E-Government, in: E-Government Series, I.C.f.t.B.o. Government, Editor 2004, IBM Center for the Business of Government: Washington, D.C.

[47] E. Swallow, "Best Social Media Customer Service" Finalists Discuss Their Success, Mashable.com, Editor 2010.

[48] D. Terdiman, Study: Wikipedia as accurate as Britannica, CNET News, 2005. 
[49] The White House, Presidential Memorandum - Accountable Government Inititiave, T.W. House, Editor 2010: Washington, DC.

[50] C.J. Tolbert and K. Mossberger, The Effects of E-Government on Trust and Confidence in Government, Public Administration Review 66(3) (2006), 354-369.

[51] United States Congress, E-Government Act of 2002, in: H.R. 2458, T. Congress, ed., Washington, DC, 2002.

[52] United States Department of Justice, Freedom of Information Act, 2008 cited 2009; Available from: http://foia.state.gov/.

[53] K. Unsworth and A. Townes, Transparency, participation, and cooperation: A case study evaluating Twitter as a social media interaction initiative, in: The Proceedings of the 13th Annual International Conference in Digital Government, d.go'12. 2012. College Park, MD: dg.O.

[54] D.M. West, E-Government and the Transformation of Service Delivery and Citizen Attitudes, Public Administration Review 64(1) (2004), 15-27.

[55] D.C. Wyld, The blogging revolution: Government in the age of Web 2.0, I.C.f.t.B.o. Government, Editor 2007: Washington, DC.

[56] S. Zuboff, Automate/Informate: The two faces of intelligent technologies, Organizational Dynamics 14(2) (1985), 5-18. 